hoc Viêt Nam, 497(2), 170-73.

3. Phừng Thị Bích Thủy (2018), "Xác định tỷ lê nhiêm adenovirus bằng kỹ thuật Realtime PCR và môt số đặc điểm dịch tễ ở trẻ em điều trị tại bênhh viển Nhi Trung Ương", Tạp chí nghiên cứu y học, 115(6), 73-79.

4. Trân Thị Thưy, Đào Minh Tuấn, Pham Thu Hiền (2018), "Đặ̆c điểm lâm sàng, cận lẩm sàng viêm phổi có nhiếm adenovirus ở trẻ từ 2 tháng đến 5 tuổi điều trị tại Bênh viện Nhi Trung ương năm 20172018", Tạp chí Y học Việt Nam, 471(1), 125-29.

5. Li L., Woo Y. Y., de Bruyne J. A., et al. (2018), "Epidemiology, clinical presentation and respiratory sequelae of adenovirus pneumonia in children in Kuala Lumpur, Malaysia", PLoS One, 13(10), pp. e0205795.

6. Liu L., Oza S., Hogan D., et al. (2016), "Global, regional, and national causes of under-5 mortality in 2000-15: an updated systematic analysis with implications for the Sustainable Development Goals", Lancet, 388(10063), pp. 3027-35.

7. Zampoli M. and Mukuddem-Sablay Z. (2017), "Adenovirus-associated pneumonia in South African children: Presentation, clinical course and outcome", S Afr Med J, 107(2), pp. 123-26.

\title{
ĐẶC ĐIỂM RỐI LOẠN ĐÔNG MÁU TRÊN BÊ̂NH NHI SỐC NHIỄ̂M KHUẨN TẠI KHOA ĐIỀU TRI TÍCH CỰC BỆNH VIỆN NHI TRUNG ƯƠNG
}

\section{TÓM TẮT}

Mục tiêu: Xác định đặc điểm lâm sàng, cận lẫ̂m sàng của rối loạn đồng máu trên bệnh nhi sốc nhiếm khuẩn tại khoa Điều trị tích cực, Bệnh viện Nhi Trung Ương. Đối tượng và phương pháp: Nghiên cứu mô tả trên 56 trẻ được chẩn đoán sốc nhiêmm khuẩn từ 08/2019 đến 08/2020. Kết quả: Tuổi trung vị: 7,5 tháng. Biểu hiện lâm sàng của rối loạn đông máu bao gồm: Xuất huyết và huyết khối gặp với tỷ lệ lần lượt là $19,7 \%$ và $1,8 \%$. 100\% bênh nhi có bất thường xét nghiệm đông máu cơ bản; bão gôm: tăng đông $(30,4 \%)$, giảm đông $(16,1 \%)$, hỗn hợp $(53,5 \%)$. Kết luận: Tỷ lệ RLĐM ở trẻ bị sốc nhiếm khuẩn cao, nhưng tỷ lệ xuất huyết và huyết khối trên lâm sàng thấp. Phát hiện sớm RLĐM cân kết hợp các dấu hiệu lâm sàng và xét nghiệm đông máu giúp chỉ định phương pháp điều trị hợp lý và kịp thời.

Tư khoá: Sốc nhiếm khuẩn, rối loạn đông cầm máu, tăng đông, giảm đông.

\section{SUMMARY}

\section{CHARACTERISTICS OF HEMOSTATIC} DISORDER IN PEDIATRIC SEPTIC SHOCK PATIENTS ADMITTED INTENSIVE CARE UNIT OF THE NATIONAL CHILDREN'S HOSPITAL

Objectives: To determine the clinical and laboratory characteristics of hemostatic disorder in pediatric septic shock patients admitted to the pediatric intensive care unit of the National Children's Hospital. Subjects and methods: This observational study recruited 56 cases with septic shock between August 2019 and August 2020. Results: The median age was 7.5 months (range, 1-205 months). The frequency of

\footnotetext{
${ }^{1}$ Bệnh viện Nhi Trung ương

2 Trường Đai hoc Y Hà Nôi

Chịu trách nhiệm chính: Tạ Anh Tuấn

Email: drtuanpicu@gmail.com

Ngày nhận bài: 11.5.2021

Ngày phản biên khoa học: 28.6.2021

Ngày duyệt bài: 12.7.2021
}

\section{Tạ Anh Tuấn ${ }^{1}$, Nguyễn Thị Thu Hà ${ }^{2}$}

clinical hemorrhage and thrombosis was $19.7 \%$ and $1.8 \%$, respectively. All children were abnormal in at least one of the conventional coagulation parameters; included: hypercoagulability $(30.4 \%)$, hypocoagulability $(16.1 \%)$, and mixed tendency $(53.5 \%)$. Conclusion: The incidence of coagulation abnormality in pediatric with septic shock was high, though most children without clinical hemorrhage and thrombosis. Therefore, this highlights the need for a combination of clinical and laboratory symptoms in the early identification of hemostatic disturbance relating to appropriate and timing treatment.

Keywords: Septic shock, hemostatic disturbance, hypercoagulability, hypocoagulability.

\section{I. ĐĂT VẤN ĐỀ}

Nhiễm khuẩn huyết (NKH) là một trong những nguyên nhân gây tử vong cao ở trẻ em, nhất là trẻ em dưới 5 tuổi. Nhiểm khuẩn huyết có thể tiến triển tới nhiễm khuẩn nặng (NKN), sốc nhiễm khuẩn (SNK) với biến chứng suy chức năng đa cơ quan dẫn đến tử vong [1]. Trong sốc nhiếm khuẩn, rối loạn đông máu (RLĐM) là một biến chứng thường gặp với tỷ lệ biến đổi theo từng nghiên cứu [3], [7]. Rối loạn đông máu có thể biểu hiện từ biên đổi nhẹ cho đến hiện tượng đông máu rải rác trong lòng mạch (Disseminated intravascular coagulation - DIC), đây là nguyên nhân hình thành huyết khối lan tỏa trong vi mạch dẫn đên tình trạng suy chức năng đa cơ quan và làm tăng nguy cơ tử vong [1],[2]. Do đó, xác định đặc điểm rối loạn đông máu nhằm lựa chọn các phương pháp điều trị kịp thời và hợp lý đóng vai trò quan trọng trong thực hành lâm sàng. Với giai đoạn tăng đông, chỉ định liệu pháp kháng đông kịp thời nhằm giảm sự lan rộng của huyết khối, giảm tình trạng suy chức năng đa cơ quan. Ngược lại, với giai đoạn giảm đông, liệu pháp truyền các chế phẩm máu phù 
hợp với tình trạng suy kiệt của hệ thống đông máu làm cải thiện tiên lượng và hạn chế biến chứng chảy máu. Chính vì vậy, nghiển cứu được tiến hành với mục tiêu:

1. Mô tả đặc điểm lâm sàng của rôi loạn đông máu trên bệnh nhi sốc nhiễm khuẩn tại khoa Điều trị tích cực, Bệnh viện Nhi Trung Ương.

2. Mô tả đặc điểm rối loạn của các chỉ số đông máu cơ bản trên bệnh nhi sốc nhiễm khuân tại khoa Điều trị tích cực, Bệnh viện Nhi Trung Uơng.

\section{II. ĐỐI TƯợNG VÀ PHƯƠNG PHÁP NGHIÊN CỨU \\ 1. Đối tượng nghiên cứu \\ *Tiêu chuấn lưa chon:}

- Bệnh nhân đã điêu trị tại khoa Điều trị tích cực, Bệnh viện Nhi Trung Ương trong thời gian từ tháng 08/2019 đến tháng 08/2020, được chẩn đoán sốc nhiễm khuẩn theo tiêu chuẩn Hội nghị quốc tế thống nhất về nhiễm khuẩn trẻ em năm 2005 (International Pediatrics Sepsis Consensus Conference - IPSCC, 2002) tại San Antonio, Texas, Hoa Kỳ [1].

- Tuổi nghiên cứu từ 1 tháng - 16 tuổi.

*Tiêu chuấn loai trừ:

- Trẻ đang được điêu trị thuốc chống đông, đang điều trị các bệnh gan mật.

- Trẻ có tiền sử rối loạn đông máu bẩm sinh.

- Không đủ thông tin hoặc sai sót thông tin trong hồ sơ bệnh án.

\section{Phương pháp nghiên cứu}

- Thiết kế nghiên cứu: nghiên cứu mô tả cắt ngang, tiến cứu.

- Phương pháp lấy mẫu: lấy mẫu thuận tiện. Trẻ được chẩn đoán SNK được thu thập số liệu theo mẫu bệnh án chung.

- Biến nghiên cứu:

+ Biến nghiên cứu lâm sàng: tuổi, giới, xuất huyết dưới da, niêm mạc, huyết khối.., tiền sử bệnh nền, suy đa tạng, điểm suy đa tạng (PELOD-2), điểm nguy cơ tử vong (PRISM III), tỷ lệ tử vong.

+ Biến nghiên cứu cận lâm sàng: các xét nghiệm cơ bản như công thức máu, tiểu cầu, đông máu cơ bản, d-dimer (bảng 2.1), chức năng gan thận, cấy máu...và các xét nghiệm khác theo hướng dẫn chẩn đoán điều trị NHK của Bệnh viện Nhi Trung Ương.

+ Thời điểm đánh giá biến nghiên cứu: với các biến lâm sàng và cận lâm sàng được đánh giá tại thời điểm 24 giờ đầu vào viện, nểu trong ngày xét nghiệm được làm nhiều lần thì lấy kết quả xấu nhất. Riêng biến tử vong sẽ đánh giá tại thời điểm bệnh nhân ra khỏi khoa.

- Một số tiêu chuẩn áp dụng trong nghiên cứu:

+ Tiêu chuẩn chẩn đoán suy chức năng cơ quan: theo định nghĩa của IPSCC-2005: Suy tuần hoàn, suy hô hấp, suy thần kinh trung ương, suy thận, suy gan, suy huyết học, suy đa cơ quan khi $\geq 2$ cơ quan bị suy [1].

+ Rối loạn đông máu: chúng tôi phân loại các trạng thái rối loạn với định nghĩa được trình bày tại bảng 2.2: DIC (Có/ không), theo trạng thái đông máu (bình thường/ tăng đông/ giảm đông/ hỗn hợp), theo tình trạng tiêu sợi huyết (có/ không).

+ Tiêu chuẩn chẩn đoán DIC: theo Hiêp hôi Đông cầm máu và Huyết khối Quốc tế (International Society for Haemostasis and Thrombosis - ISTH) [4].

Bảng 2.1. Dải tham chiếu đông máu cơ bản [5]

\begin{tabular}{|c|c|c|}
\hline Biến & Đơn vị & $\begin{array}{c}\text { Dải tham } \\
\text { chiếu }\end{array}$ \\
\hline Số lượng tiếu câu (SLTC) & $\mathrm{G} / \mathrm{L}$ & $150-400$ \\
\hline Tỷ lệ prothrombin (PT\%) & $\%$ & $70-140$ \\
\hline $\begin{array}{c}\text { Thời gian prothrombin } \\
\text { (Prothrombin Time - PTs) }\end{array}$ & giây & $10-14$ \\
\hline $\begin{array}{c}\text { Tý lệ chuấn hóa quốc tế } \\
\text { (International Normalized } \\
\text { Ratio-INR) }\end{array}$ & không & $0,9-1,1$ \\
\hline $\begin{array}{c}\text { Thời gian thromboplastin } \\
\text { tứng phân (Partial } \\
\text { thromboplastin time - APTT) }\end{array}$ & giây & $\begin{array}{c}\text { *APTT kéo } \\
\text { dài: }>8-10\end{array}$ \\
\hline Fibrinogen & $\mathrm{g} / \mathrm{L}$ & $2-4$ \\
\hline D-Dimer & $\mathrm{ng} / \mathrm{mL}$ & $<500$ \\
\hline
\end{tabular}

Bảng 2.2. Các trạng thái rối loạn đông máu [5]

\begin{tabular}{|c|c|c|}
\hline ói & dông & Định nghĩa \\
\hline & IC & $\begin{array}{r}\text { Thang điểm } \mathrm{D} \\
20\end{array}$ \\
\hline & & $\begin{array}{l}\text { Các giá trị trong giới hạn } \\
\text { khoảng tham chiếu (bảng } 2.1\end{array}$ \\
\hline $\begin{array}{l}\text { Trạng } \\
\text { thái }\end{array}$ & $\begin{array}{l}\text { Tăng } \\
\text { đông }\end{array}$ & $\begin{array}{l}\text { Tăng số lu } \\
\text { fibrin }\end{array}$ \\
\hline $\begin{array}{l}\text { dong } \\
\text { máu }\end{array}$ & $\begin{array}{l}\text { Giảm } \\
\text { đông }\end{array}$ & $\begin{array}{l}\text { Giảm tiếu cầu, PT\%, } \\
\text { fibrinogen, tăng APTTs }\end{array}$ \\
\hline & $\pi$ & đôn \\
\hline
\end{tabular}

Tiêu sợi huyết Tăng D-dimer, giảm fibrinogen

- Xì̛ lý số liệu: Bằng phần mềm SPSS 20.0.

\section{KẾT QUẢ NGHIÊN CứU}

Trong thời gian nghiên cứu từ tháng 8/2019 đến tháng 8/2020, chúng tôi đã thu thập được 56 bệnh nhân đủ tiêu chuẩn đưa vào nghiển cứu. Kết quả nghiên cứu được trình bày dưới đây.

Bảng 3.1.Một số đặc điểm chung của đôi tượng nghiên cứu

\begin{tabular}{|c|c|}
\hline Đặc điểm & $\begin{array}{c}\text { Số bệnh nhân } \\
(\mathrm{n}=56)\end{array}$ \\
\hline
\end{tabular}




\begin{tabular}{|c|c|c|}
\hline \multicolumn{2}{|c|}{$\begin{array}{c}\text { Tuối (tháng), trung vị } \\
\text { (tứ phân vị) }\end{array}$} & $\begin{array}{c}7,5 \\
(3-42,5)\end{array}$ \\
\hline \multirow{2}{*}{ Giới } & Nam, $\mathrm{n}(\%)$ & $32(57,1 \%)$ \\
\cline { 2 - 3 } & Nứ, $\mathrm{n}(\%)$ & $24(42,9 \%)$ \\
\hline \multirow{2}{*}{$\begin{array}{c}\text { Bê̂nh lý } \\
\text { nền }\end{array}$} & Có, $\mathrm{n}(\%)$ & $8(14,3 \%)$ \\
\cline { 2 - 3 } Không, $\mathrm{n}(\%)$ & $48(85,7 \%)$ \\
\hline \multirow{2}{*}{ Suy tạng } & Kuy 2 cơ quan, $\mathrm{n}(\%)$ & $56(100 \%)$ \\
\cline { 2 - 3 } & Suy > 2 cơ quan, $\mathrm{n}(\%)$ & $42(75 \%)$ \\
\hline PRISM III, trung vị (tứ phân vị) & $10,5(7-17,8)$ \\
\hline PELOD-2, trung vị (tứ phân vị) & $8(6-11)$ \\
\hline Cấy máu dương tính, $\mathrm{n}(\%)$ & $17(30,4 \%)$ \\
\hline \multicolumn{2}{|c|}{ Tứ vong, $\mathrm{n}(\%)$} & $17(30,4 \%)$ \\
\hline
\end{tabular}

Nhận xét: Tuối trung vị là 7,5 tháng tuối. Tỳ lệ nam là $57,1 \%$; tỷ lệ nữ là $42,9 \%$. Điểm PELOD-2 và điểm PRISM III trung vị lần lượt là 8 và 10,5 . Tỷ lệ cấy máu dương tính là $30,4 \%$. Tỷ lệ tử vong là $30,4 \%$.

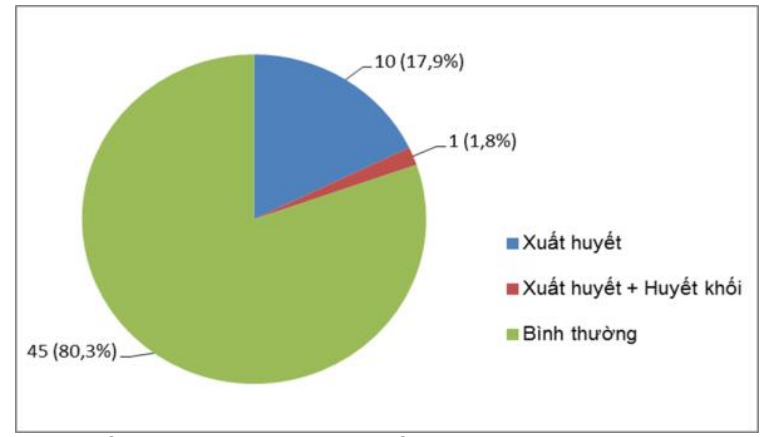

Biểu đồ 3.1. Đặc điểm lâm sàng của rôí loạn đông máu

Nhận xét: Đa số bệnh nhân không có biểu hiện xuất huyết $(80,3 \%) \cdot 11 / 56(19,7 \%)$ trường hợp biểu hiện xuất huyết và $1 / 56(1,8 \%)$ trường hợp biểu hiện huyết khối trên lâm sàng.

Bảng 3.2. Đặc điểm cận lâm sàng của rôi loạn đông cầm máu trong 24 giờ đâu

\begin{tabular}{|c|c|c|c|c|}
\hline \multicolumn{4}{|c|}{ Phân loại } & DCMCB, D-Dimer n (\%) \\
\hline \multirow{3}{*}{$\begin{array}{l}\text { Chung } \\
(n=56)\end{array}$} & \multicolumn{3}{|c|}{ Bình thường } & $0(0 \%)$ \\
\hline & \multicolumn{3}{|c|}{ Rối loạn đông máu } & $56(100 \%)$ \\
\hline & \multirow{4}{*}{$\begin{array}{c}\text { Tình trạng } \\
\text { đông máu } \\
(\mathrm{n}=56)\end{array}$} & \multicolumn{2}{|c|}{ Bình thường } & $0(0 \%)$ \\
\hline \multirow{16}{*}{$\begin{array}{l}\text { Rối } \\
\text { loạn } \\
\text { đông } \\
\text { máu }\end{array}$} & & \multicolumn{2}{|c|}{ Tăng đông } & $17(30,4 \%)$ \\
\hline & & \multicolumn{2}{|c|}{ Giảm đông } & $9(16,1 \%)$ \\
\hline & & \multicolumn{2}{|c|}{ Hôn hợp } & $30(53,5 \%)$ \\
\hline & \multirow{3}{*}{$\begin{array}{l}\text { Tiêu sợi } \\
\text { huyết } \\
(n=56)\end{array}$} & \multirow{2}{*}{\multicolumn{2}{|c|}{$\begin{array}{c}\text { Có } \\
\text { Không } \\
\end{array}$}} & $3(5,4 \%)$ \\
\hline & & & & $53(94,6 \%)$ \\
\hline & & \multicolumn{2}{|c|}{$\mathbf{P}$} & 0,000 \\
\hline & \multirow{10}{*}{$\begin{array}{c}\text { DIC } \\
(n=56)\end{array}$} & \multirow{5}{*}{$\begin{array}{c}\text { Có } \\
(n=26 ; \\
46,4 \%)\end{array}$} & Bình thường & $0(0 \%)$ \\
\hline & & & Tăng đông & $0(0 \%)$ \\
\hline & & & Giảm đông & $8(30,8 \%)$ \\
\hline & & & Hôn hợp & $18(69,2 \%)$ \\
\hline & & & Tiêu sợi huyết & $3(11,5 \%)$ \\
\hline & & \multirow{5}{*}{$\begin{array}{c}\text { Không } \\
\begin{array}{c}(\mathrm{n}=30 ; 53,6 \\
\%)\end{array}\end{array}$} & Bình thường & $0(0 \%)$ \\
\hline & & & Tăng đông & $17(56,7 \%)$ \\
\hline & & & Giảm đông & $1(3,3 \%)$ \\
\hline & & & Hôn hợp & $12(40 \%)$ \\
\hline & & & Tiêu sợi huyết & $0(0 \%)$ \\
\hline
\end{tabular}

Nhận xét: Tất cả bệnh nhi có RLĐM (100\%), trong đó tỷ lệ DIC chiếm 46,4\%. Xét rối loạn về trạng thái đông máu: Rổi loạn hỗn hợp (tăng đông và giảm đông) chiếm tỷ lệ lớn nhất $(53,5 \%)$, sau đó là tăng đông $(30,4 \%)$, giảm đông $(16,1 \%)$. Tình trạng tiêu sợi huyết chỉ phát hiện ở 3/56 (5,4\%) trường hợp.

\section{BÀN LUÂN}

Qua nghiên cứu 56 trẻ sốc nhiễm khuẩn, nghiên cứu nhận thấy tuổi của đối tượng nghiên cứu có giá trị trung vị là 7,5 tuổi; tuổi thấp nhất là 1 tháng và cao nhất là 205 tháng (Bảng 3.1). Kết quả nghiên cứu này cũng phù hợp với một số nghiên cứu tại Việt Nam và trên thế giới cho thây trẻ dưới 1 tuổi chiếm tỷ lệ cao nhất trong sốc nhiễm khuẩn. Điều này có thể giải thích là do hệ thống miễn dịch của lứa tuổi này chưa trưởng thành nên chưa có đáp ứng đầy đủ và dễ dàng nhạy cảm với các tác nhân gây bệnh [6].
Biến chứng xuất huyết trong nghiên gặp với tỷ lệ 20\% (Biểu đồ 3.1). Trong đó, xuất huyết ở da, niêm mạc gặp nhiều nhất với 7 trường hợp, chủ yếu xuất huyết ở mức độ nhe và trung bình với biểu hiện chấm, nốt xuất huyết dưới da hoặc chảy máu chân răng, xuất huyết tại nợi tiêm truyền và vết mổ có 1 trường hợp, 2 trường hợp nặng ghi nhận có xuất huyết não. Trong khi đó, biến chứng huyết khối chỉ ghi nhận ở 1 trường hợp với biểu hiện nhồi máu não và xuất huyết nã̃o xảy ra đồng thời. Nghiên cứu của chúng tôi ghi nhận tỷ lệ biến chứng xuất huyết thấp hơn 
so với các nghiên cứu khác. Theo nghiên cứu của Lê Thanh Cẩm tại Bệnh viện Nhi Đồng I cho thấy: Tỷ lệ xuất huyết dưới da, niêm mạc, nội tạng và cả da niêm mạc, nội tạng ở bệnh nhân sốc nhiễm khuẩn lần lượt là $29,91 \% ; 32,71 \%$ và 18,69\% [7]. Theo Phùng Nguyê̂n Thế Nguyên, tỷ lệ xuất huyết da niêm mạc tại thời điểm 24 giờ sau chẩn đoán là $41,7 \%$; trong đó xuất huyết da dày nhiêuu hơn xuất huyết da [8]. Tỷ lệ xuất huyết trong nghiên cứu của chúng tôi thấp hơn so với các nghiên cứu khác có thể là do sự khác biêt về cỡ mẫu, mức độ nặng giữa quần thể bệnh nhân trong các nghiên cứu, do sự khác biêt về phương tiện điều trị cũng như các khuyến cáo điều trị hiện nay liên tục được cập nhật. Mặt khác nghiên cứu cũng nhân thấy sở dĩ tỷ lệ biển chứng xuất huyết cao hơn so với biến chứng huyết khối có thể giải thích là do trong giai đoạn sốc nhiễm khuẩn, rối loạn đông máu chủ yếu là giai đoạn giảm đông, tình trạng này có thể là kết quả của sự tiêu thụ quá mức các yếu tố đông máu, do đó gây nguy cơ xuất huyết cao hơn. Hơn nữa, tình trạng đông máu rải ráctrong lòng mạch thường biểu hiện bằng sự có mặt của huyết khối lan tỏa trong các vi mạch gây thiếu máu cục bộ và rối loạn chức năng cơ quan. Trong nghiên cứu của chúng tôi ghi nhận $100 \%$ bệnh nhân có suy 2 cơ quan (Bảng 3.1); hiện tượng này có thể giả thuyết rằng tình trang suy đa cơ quan có thể là dấu hiệu sớm của biến chứng huyết khối hơn là khi đã có biểu hiện huyết khối trên lâm sàng.

Bình thường khi cơ thể khỏe manh, cơ thể luôn có sự cân bằng giữa hệ thống đông cầm máu và hệ thống ly giải fibrin. Rối loạn đông máu trong nhiễm khuẩn huyết xảy ra do sự tác động của các yếu tố như: Nội độc tố của vi khuẩn Gram (-) hay ngoại độc tố của vi khuẩn Gram $(+) \ldots$ vào bất cứ một khâu nào của các hê thống này [5]. Trong nhiễm khuẩn huyết, rối loạn đông máu được kích hoạt bằng sự hoat hóa quá mức các yếu tố đông máu, sự suy giảm hệ thống kháng đông và sự suy giảm hể thống "fibrinolysis". Các phản ứng này dẫn đển trạng thái tăng đông trong giai đoạn đâu, giúp hình thành hàng rào "Immunothrombosis" có vai trò hạn chế sự xâm nhập của các các vi sinh vật vào các mô xung quanh hoặc hệ tuần hoàn [2]. Tuy nhiên, sự hoạt hóa quá mức phản ứng này dẫn đến hình thành huyết khối vi mạch; đặc biệt là hiện tượng đông máu rải rác trong lòng mạch gây suy chức năng đa cơ quan. Đồng thời, quá trình tiêu thụ các yếu tố đông máu cuối cùng dẫn đến tình trạng giảm đông có thể gây ra biến chứng xuất huyết nặng nề [2]. Nghiên cứu cho thấy $100 \%$ bệnh nhân có bất thường ít nhất một trong số các chỉ số đông máu cơ bản, trong đó DIC chiếm $46,4 \%$. Theo trạng thái đông máu: Tình trạng hỗn hợp (cả tăng đông và giảm đông) chiếm tỷ lệ cao nhất $53,5 \%$; sau đó là tình trạng tăng đông với $30,4 \%$; chỉ có $16,1 \%$ trường hợp ghi nhận có tình trạng giảm đông đơn thuần (Bảng 3.2). Tỷ lệ rối loạn đông máu hỗn hợp có thể giải thích là do nhược điểm của các xét nghiệm ĐMCB đã được đề cập đến trong nhiều nghiển cứu với khả năng cho kết quả khó xác định về tình trang đông máu của bênh nhân, cự thể là xu hướng tăng đông ưu thễ đối với các chì số fibrinogen và d-dimer; ngược lại, tình trạng giảm đông lại ưu thế ở các chỉ số PT, APTT, thrombin [9]. Chúng tôi ghi nhận chưa có nghiên cứu nào tại Việt Nam so sánh về phân bố tình trạng RLĐM trên trẻ nhiễm khuẩn huyết dựa trên xét nghiệm ĐMCB. Trên thế giới, nhiều nghiên cứu trên cả trẻ em và người trưởng thành cũng đã mô tả phân bố về tỷ lệ tăng đông, giảm đông, bình thường trong nhiễm khuẩn huyết. Trong đó, tỷ lệ tăng đông được ghi nhận trên các nghiên cứu ở người trưởng thành từ 30\% $100 \%$. Tuy nhiên, tình trạng tăng đông thường biểu hiện trong giai đoạn sớm của nhiểm khuẩn huyết, ngược lại, sự tiến triển đến tình trạng giảm đông thường biểu hiện ở giai đoạn muộn nhiễm khuẩn huyết như nhiễm khuẩn nặng hoặc sốc nhiễm khuẩn.

Bên cạnh các rối loạn về tình trạng đông máu, nghiên cứu cũng ghi nhận 3 trường hợp $(5,4 \%)$ có tiêu sợi huyết (Bảng 3.2$)$. Điều này phù hợp với đặc điểm của DIC trong sốc nhiếm khuẩn chủ yếu là tình trạng giảm hoặc bình thường của hê fibrinolysis; khác với DIC do các nguyên nhân khác như chấn thương, bỏng, phẫu thuật thường biểu hiện tình trạng tăng hoạt hóa của hệ fibrinolysis.

\section{KẾT LUẦN}

Tỷ lệ rối loạn đông máu ở trẻ bị sốc nhiễm khuẩn khá cao, nhưng tỷ lệ xuất huyết và huyết khối trên lâm sàng thấp. Chính vì vậy, trong thực hành lâm sàng để phát hiện sớm rối loạn đông máu ở bệnh nhi nhiễm khuẩn huyết cần kết hợp đánh giá giữa lâm sàng và xét nghiệm đông máu nhằm đưa ra được phương pháp điêu trị hợp lý và kịp thời.

\section{TÀI LIỆU THAM KHẢO}

1. Goldstein B, Giroir B, Randolph A.
International 
dysfunction in pediatrics. Pediatric Critical Care Medicine. 2005;6(1):2-8.

2. Saracco $\mathbf{P}$, Vitale $\mathbf{P}$, Scolfaro $\mathbf{C}$, et al. The coagulopathy in sepsis: significance and implications for treatment. Pediatric Reports. 2011;3(4):30.

3. Sharma A. Plasma Fibrinogen and D-dimer in Children With Sepsis: A Single-center Experience. Iranian Journal of Pathology. 2018;13(02):272-275.

4. Toh C.H, Hoots W.K. The scoring system of the Scientific and Standardisation Committee on Disseminated Intravascular Coagulation of the International Society on Thrombosis and Haemostasis: a 5-year overview. Journal of Thrombosis and Haemostasis. 2007;5(3):604-606.

5. Nguyễn Anh Trí. Đông máu ứng dụng trong lâm sàng. Nhà xuất bản Y học, Hà Nội.(2002).
6. Vekaria-Hirani V, Kumar R, Musoke R.N, et al. Prevalence and Management of Septic Shock among Children Admitted at the Kenyatta National Hospital, Longitudinal Survey. International Journal of Pediatrics. 2019, accessed: 09/20/2020.

7. Lê Thanh Cẩm, Bùi Quốc Thắng. Rối loạn đông máu trên bệnh nhân nhiễm khuẩn huyết tại bệnh viện Nhi Đồng I (từ 2008-2010). Tạp chí Y học TP Hổ Chí Minh. 2012; 16(2):54-58.

8. Phùng Nguyển Thế Nguyên. Rối loan đông máu trong sốc nhiếm khuẩn tré em. Tạp chí Y học TP. Hồ Chí Minh. 2014; 18(1):368-373

9. Andersen MG, Hvas CL, Tønnesen $E$, et al. Thromboelastometry as a supplementary tool for evaluation of hemostasis in severe sepsis and septic shock. Acta Anaesthesiol Scand. 2014;58(5):525-533.

\section{KẾT QUẢ XA PHẪU THUÂT THAY KHỚP HÁNG TOÀN PHẦN KHÔNG XI MĂNG ĐIỀU TRI THOÁI HOÁ KHỚP HÁNG TẠI BỆNH VIỆN VIỆT ĐỨC}

\section{TÓM TẮT}

Thoá hoá khớp háng là bệnh thường gặp ở người cao tuổi, là nguyên nhân chính làm giảm chức năng khớp háng. Mục tiêu: Đánh giá kết quả xa phẫu thuật thay khớp háng toàn phân không xi măng điều trị thoái hoá khớp háng. Phương pháp: nghiên cứu mô tả cắt ngang 150 bệnh nhân với 175 khớp háng thoái hoá tiên phát, được thay khớp háng toàn phân không xi măng, thời gian từ tháng 5/2011-3/2021 tại viện Chấn thương chỉnh hình bệnh viện Việt Đức. Tỷ lệ nam/nữ là 3,5. Tuổi trung bình lúc phẫu thuât 68,2 (từ 65 tuổi đến 78 tuổi). Thời gian theo dõi lâu nhất 10 năm, ngắn nhất 5 năm, trung bình là 7 năm 3 tháng. Kết quả: Đánh giá theo thang điểm của Harris, kết quả rất tốt chiếm $47,5 \%$, tốt chiếm $42 \%$, khá chiếm $8,0 \%$ và trung bình chiếm $2 \%$. 01 trường hợp kết quả xấu chiếm $0,5 \%$. Kết luận: Phẫu thuât thay khớp háng toàn phân không xi măng mang lại kết quả tốt, tuy nhiên cân tiếp tục theo dõi và đánh giá trong thời gian dài hơn.

Tư khóa: kết quả xa, thay khớp háng toàn phân không xi măng.

\section{SUMMARY}

\section{THE LONGTERM RESULTS OF CEMENTLESS TOTAL HIP ARTHROPLASTY IN VIET DUC ARY HOSPITAL}

158 patients with 175 hips were treated with cementless total hip arthroplasty from 5/2011-3/2021

\footnotetext{
${ }^{1}$ Trường Đại Hoc Y Hà Nội

²Bênh viện HN Việt Đức

Chịu trách nhiệm chính: Dương Đình Toàn

Email: duongdinhtoan@hmu.edu.vn

Ngày nhận bài: 17.5.2021

Ngày phản biên khoa hoc: 1.7.2021

Ngày duyệt bài: 16.7.2021
}

\section{Dương Đình Toàn ${ }^{1,2}$, Võ Quốc Hưng ${ }^{2}$}

in the Traumatology and Orthopeadics Institute, VietDuc Hospital. Average age 68,2 (from 65 to 78 years old). Results follow-up times from 5 to 10 years (average 7 years and 3 months). The results were evaluated according to the Harris hip score. Excelent result is $47,5 \%$, good $42 \%$, fair $8 \%$, moderate and poor 2,5\% The complications composed: there were 3 superficial infections, fracture of the femur were 1 patients, loosening of the femoral component were zero patients. Cementless total hip replacement surgery provides good results, but requires continued monitoring and evaluation over a longer period of time

Key words: long-term results, cementless tota hip arthroplasty.

\section{I. ĐĂTT VẤN ĐỀ}

Hiện nay, phẫu thuật thay khớp háng nhân tạo là giải pháp cuối cùng để điều trị một số bệnh lý khớp háng sau giai đoạn điều trị nội khoa, trong đó phổ biến nhất là thoái hoá khớp háng. Tại Việt Nam, hàng năm có hàng ngàn bệnh nhân được thay khớp háng, theo nhiều nghiên cứu trong nước, kết quả điều trị phẫu thuật thay khớp háng rất khả quan trong giai đoạn đầu dưới 5 năm.

Tại Bệnh viện Việt Đức, phẫu thuật thay khớp háng được bắt đầu vào năm 1990. Tuy nhiên, phẫu thuật thay khớp háng toàn phần không xi măng chỉ bắt đầu được thực hiện từ đầu những năm 2000, cho đến nay, sau 20 năm, đủ thời gian theo dõi dài, chúng tôi thấy rằng cần thiết phải tổng kết, đánh giá kết quả xa của kỹ thuật trên, đồng thời rút ra một số bài học kinh nghiệm về chỉ định, kỹ thuật, cách xử lý những tai biến, biến chứng.... Với mục đích như vậy, 